\title{
Antiproliferative and antimetastatic effects of emodin on human pancreatic cancer
}

\author{
AN LIU $^{1 *}$, HUI CHEN ${ }^{1 *}$, WEITIAN WEI ${ }^{1}$, SHENG YE $^{2}$, WEI LIAO $^{1}$, \\ JIANMING GONG $^{2}$, ZHENGCAI JIANG ${ }^{1}$, LIAN WANG ${ }^{1}$ and SHENGZHANG LIN ${ }^{1}$ \\ ${ }^{1}$ Department of Surgery, The Second Affiliated Hospital of Wenzhou Medical College, \\ No. 109, West Xue-yuan Road, Wenzhou 325027; ${ }^{2}$ The First Affiliated Hospital of \\ Wenzhou Medical College, No. 2, Fu-xue Lane, Wenzhou 325000, P.R. China
}

Received November 25, 2010; Accepted January 7, 2011

DOI: $10.3892 / o r .2011 .1257$

\begin{abstract}
Emodin (1, 3, 8-trihydroxy-6-methylanthraquinone) is an active constituent isolated from the root of Rheum palmatum $\mathrm{L}$ and is the main effective component of some Chinese herbs and plants. Pharmacological studies have demonstrated that emodin exhibits anti-cancer effects on several human cancers. However, the molecular mechanisms of emodin-mediated tumor regression have not been fully defined. This study was performed to investigate the antiproliferative and antimetastatic effects of emodin on pancreatic cancer in vitro and in vivo. Our results showed that emodin induced a higher percentage of growth inhibition and apoptosis in the pancreatic cancer cell line SW1990 compared to that of control, and emodin suppressed the migration and invasion of SW1990 cells in a dose-dependent manner. To investigate the possible mechanisms involved in these events, we performed electrophoretic mobility shift assay (EMSA) and Western blot analysis, and found that emodin significantly down-regulated NF- $\mathrm{KB}$ DNA-binding activity, survivin and MMP-9 in SW1990 cells. Moreover, the expression of cleaved caspase-3 was up-regulated in SW1990 cells after treatment with emodin. In addition, a metastatic model simulating human pancreatic cancer was established by orthotopic implantation of histologically intact human tumor tissue into the pancreatic wall of nude mice. Oral administration of emodin significantly decreased tumor weight and metastasis compared to control. Furthermore, the expression of NF- $\mathrm{KB}$, survivin and MMP-9 were also suppressed in
\end{abstract}

Correspondence to: Dr Shengzhang Lin, The Second Affiliated Hospital and Yuying Children's Hospital of Wenzhou Medical College, No. 109, West Xue-yuan Road, Wenzhou 325027, P.R. China

E-mail:wzf21sz@163.com

${ }^{*}$ Contributed equally

Key words: pancreatic neoplasms, emodin, transcription factor nuclear factor- $\kappa \mathrm{B}$ tumor tissues after treatment with emodin. Collectively, our results indicated that emodin exerts antiproliferative and antimetastatic activity on pancreatic cancer both in vitro and in vivo, which may be related to down-regulation of NF- $\mathrm{KB}$ and its regulated molecules such as survivin and MMP-9 proteins. Consequently, these results provide important insights into emodin as an anti-invasive agent for the therapy of human pancreatic cancer.

\section{Introduction}

Pancreatic cancer is a highly malignant neoplasm characterized by locally advanced unresectable disease or metastasis at the time of diagnosis. Current therapies are largely ineffective in this disease and the 5-year survival rate remains dismal (1). Pancreatic cancer is now one of the most common causes of cancer death worldwide. According to NIH-National Cancer Institute statistics, of the 38,000 new cases of pancreatic cancer diagnosed in 2008, 35,000 are expected to succumb to this disease. In the United States nearly all patients diagnosed with pancreatic adenocarcinoma die of a cancer-related cause (2). Complete surgical resection remains the only potentially curative treatment modality for patients with pancreatic cancer. Unfortunately, the vast majority of patients present with unresectable or metastatic disease. Even among patients undergoing a potentially curative resection, many will develop metastatic disease.

Emodin is an anthraquinone derivative from the rhizome of Rheum palmatum L (3), a plant widely used in traditional Chinese medicine as a laxative. It has been reported that emodin possesses a number of biological activities such as anti-bacterial, anti-inflammatory, and immunosuppressive effects (4). In the context of cancer, recent studies showed that emodin exerts anti-proliferative and apoptosis-inducing effects on cell lines derived from ovarian (5), lung (6) and leukemia (7). However, so far there is little evidence showing the possible effect of emodin on tumor metastasis in pancreatic cancer. Herein we investigated the inhibitory effect of emodin on cell proliferation using pancreatic cancer cell line SW1990, and whether emodin has anti-metastatic activity on pancreatic cancer in vitro and in vivo, and if so, the possible mechanisms of these actions. 
Our findings showed that emodin significantly inhibited the proliferation of pancreatic cancer in vitro and in vivo, and emodin exerts an strong anti-metastatic activity on pancreatic cancer in both in vitro and in vivo. We further demonstrated that emodin effectively suppressed $\mathrm{NF}-\kappa \mathrm{B}$, leading to decreased survivin and MMP-9 expression. These results suggest that emodin inhibits the proliferation and invasiveness of human pancreatic cancer through inhibiting $\mathrm{NF}-\kappa \mathrm{B}$ activity.

\section{Materials and methods}

Reagents. Emodin was purchased from Sigma (St. Louis, MO, USA), dissolved in dimethylsulfoxide (DMSO) to make $0.2 \mathrm{mmol} \cdot \mathrm{l}^{-1}$ stock solution. The final concentration of DMSO was $<0.1 \%$. Antibodies against survivin, MMP-9 and $\beta$-actin were obtained from Epitomics (Burlingame, CA, USA). Antibody against caspase-3 was purchased from Abcam (Cambridge, MA, USA).

Cell culture. Human pancreatic cancer cell line SW1990 was purchased from American Tissue Culture Collection (Manassas, VA, USA). The cell line was maintained in continuous exponential growth in RPMI-1640 (Gibco BRL, Grand Island, NY) supplemented with $10 \%$ fetal bovine serum (FBS) (Gibco BRL), 100 units $\cdot \mathrm{ml}^{-1}$ penicillin, and $10 \mu \mathrm{g} \cdot \mathrm{ml}^{-1}$ streptomycin in a humidified incubator containing $5 \% \mathrm{CO}_{2}$ in air at $37^{\circ} \mathrm{C}$.

Proliferation assay. Cells were seeded at a density of $4 \times 10^{3}$ per well in 96-well microtiter culture plates. After overnight incubation, medium was removed and replaced with fresh medium containing different concentrations of emodin (10, 20 and $40 \mu \mathrm{mol} \cdot \mathrm{l}^{-1}$ ) for $24 \mathrm{~h}$. On completion of incubation, cell viability was determined by WST- 8 assay (Beyotime, Shanghai, China) according to the manufacturer's instructions. Briefly, WST-8 solution was added to cells in 96-well plates, the cells were incubated at $37^{\circ} \mathrm{C}$ for $60-90 \mathrm{~min}$, and the optical density of each well was read at $450 \mathrm{~nm}$ using a microplate reader (ELX800, Bio-Tek, USA)

Flow cytometric assessment of apoptosis. The measurement of phosphatidylserine redistribution in a plasma membrane was conducted according to the protocol outlined by the manufacturer of the Annexin V-FITC/PI apoptosis detection kit (Abcam). After treatment, harvested $1 \times 10^{5}$ cells were suspended in $500 \mu 1$ of Annexin V binding buffer (1X). Annexin V-FITC $(5 \mu 1)$ and $5 \mu 1$ of PI were added and incubated with for $15 \mathrm{~min}$ in dark. Binding buffer $(500 \mu \mathrm{l}, 1 \mathrm{X})$ was added to each sample. The stained cells were analyzed directly by flow cytometry using the Cell Quest program (Becton Dickinson, San Jose, CA, USA). The average of the results from at least three samples of cells for each experimental condition is presented.

Wound healing assays. The SW1990 cells $\left(10^{4}\right.$ cells $/ 0.4 \mathrm{ml}$ RPMI-1640) were grown to confluent monolayers onto 6-wells plates for $24 \mathrm{~h}$. Cells in 6-wells plates were washed twice with PBS and a wound applied with a plastic pipette tip. The cells were washed twice with PBS, photographed under phase-contrast microscope (Olympus, Tokyo, Japan) then incubated in media with or without increasing concentrations of emodin $\left(10,20\right.$ and $\left.40 \mu \mathrm{mol}^{-1} \mathrm{l}^{-1}\right)$ at $37^{\circ} \mathrm{C}$ and $5 \% \mathrm{CO}_{2}$ for $2 \mathrm{~h}$, then the cells were gently washed with PBS. After $24 \mathrm{~h}$ of incubation, the wound area was photographed. The assays were performed in triplicate.

Invasion assays. Cells $\left(2 \times 10^{5}\right)$ suspended in serum-free RPMI-1640 containing $0.1 \%$ BSA were placed in the upper chamber, which was coated with $50 \mu \mathrm{l}$ of matrigel (Becton Dickinson) of a Transwell filter (diameter $6.5 \mathrm{~mm}$, pore size $8 \mu \mathrm{m}$; Costar, Cambridge, MA, USA), and incubated with different concentrations of emodin $\left(10,20\right.$ and $\left.40 \mu \mathrm{mol} \cdot 1^{-1}\right)$ for $2 \mathrm{~h}$. Then the cells were allowed to invade through the matrigel over a $24 \mathrm{~h}$ period at $37^{\circ} \mathrm{C}$ in $5 \% \mathrm{CO}_{2}$. Non-invasive cells in the upper side of the membrane were removed with a cotton swab, and invasive cells were stained with the crystal violet staining kit (Beyotime). Invasiveness was determined by counting cells in at least 20 random fields per well, and the extent of invasion was expressed as the average number of cells per microscopic field.

Protein extraction and Western blot analysis. After treatment, the cells were harvested in PBS and whole cell lysate was prepared by suspending the cells in $200 \mu \mathrm{l}$ of lysis buffer $\left[1 \mathrm{~mol} \cdot \mathrm{l}^{-1}\right.$ Tris- $\mathrm{HCl}(\mathrm{pH} 7.5), 150 \mathrm{mmol} \cdot \mathrm{l}^{-1} \mathrm{NaCl}, 1 \mathrm{mmol} \cdot \mathrm{l}^{-1}$ EGTA, 0.1\% Triton X-100; $0.1 \mathrm{mmol}^{-1} \mathrm{l}^{-1}$ sodium orthovanadate, $1 \mathrm{mmol} \cdot 1^{-1}$ phenylmethylsulfonyl fluoride (PMSF), and $2 \mu \mathrm{g} \cdot \mathrm{ml}^{-1}$ leupeptin, $2 \mu \mathrm{g} \cdot \mathrm{ml}^{-1}$ aprotinin]. The cells were disrupted by sonication and the total proteins were extracted by centrifuging the tubes at $4^{\circ} \mathrm{C}$ for $30 \mathrm{~min}$ at maximal microfuge speed to remove debris. For immunoblotting, each extract was prepared as above and an equivalent to $20 \mu \mathrm{g}$ total proteins was separated on SDS-PAGE, electrotransferred onto nitrocellulose membranes, and probed with specific antibodies. Detection of specific proteins was carried out with an enhanced chemiluminescence Western blotting kit according to manufacturer's instructions. The same membrane was reprobed with the anti- $\beta$-actin antibody, which was used as an internal control for protein loading.

Electrophoretic mobility shift assay. Nuclear extracts were prepared according to the method described previously (8). Briefly, respective treatment cells were washed with cold PBS and suspended in $0.15 \mathrm{ml}$ of lysis buffer [10 mmol. ${ }^{-1}$ HEPES (pH 7.9), $10 \mathrm{mmol} \cdot \mathrm{l}^{-1} \mathrm{KCl}, 0.1 \mathrm{mmol} \cdot \mathrm{l}^{-1}$ EDTA, $0.1 \mathrm{mmol} \cdot \mathrm{l}^{-1}$ EGTA, $1 \mathrm{mmol} \cdot \mathrm{l}^{-1} \mathrm{DTT}, 1 \mathrm{mmol} \cdot \mathrm{l}^{-1} \mathrm{PMSF}, 2 \mu \mathrm{g} \cdot \mathrm{ml}^{-1}$ leupeptin, $2 \mu \mathrm{g} \cdot \mathrm{ml}^{-1}$ aprotinin, and $0.5 \mathrm{mg} \cdot \mathrm{ml}^{-1}$ benzamidine]. The cells were allowed to swell on ice for $20 \mathrm{~min}$ and then $4.8 \mu \mathrm{l}$ of $10 \%$ NP40 was added. The tubes were then vigorously mixed on a vortex mixer for a few seconds and centrifuged in a microfuge. The nuclear pellet was resuspended in $30 \mu \mathrm{l}$ of ice-cold nuclear extraction buffer [20 mmol $\cdot \mathrm{l}^{-1} \mathrm{HEPES}(\mathrm{pH} 7.9), 0.4 \mathrm{~mol} \cdot \mathrm{l}^{-1}$ $\mathrm{NaCl}, 1 \mathrm{mmol} \cdot \mathrm{l}^{-1}$ EDTA, $1 \mathrm{mmol} \cdot \mathrm{l}^{-1}$ EGTA, $1 \mathrm{mmol} \cdot \mathrm{l}^{-1}$ DTT, $0.5 \mathrm{mmol} \cdot l^{-1} \mathrm{PMSF}, 2 \mu \mathrm{g} \cdot \mathrm{ml}^{-1}$ leupeptin, $2 \mu \mathrm{g} \cdot \mathrm{ml}^{-1}$ aprotinin, and $0.5 \mathrm{mg} \cdot \mathrm{ml}^{-1}$ benzamidine] and incubated on ice with intermittent mixing. The tubes were then centrifuged for $5 \mathrm{~min}$ in a microfuge at $4^{\circ} \mathrm{C}$, and the supernatant (nuclear extract) was collected in cold Eppendorf tubes and stored at $-70^{\circ} \mathrm{C}$ for later use. The protein content was measured by 
A

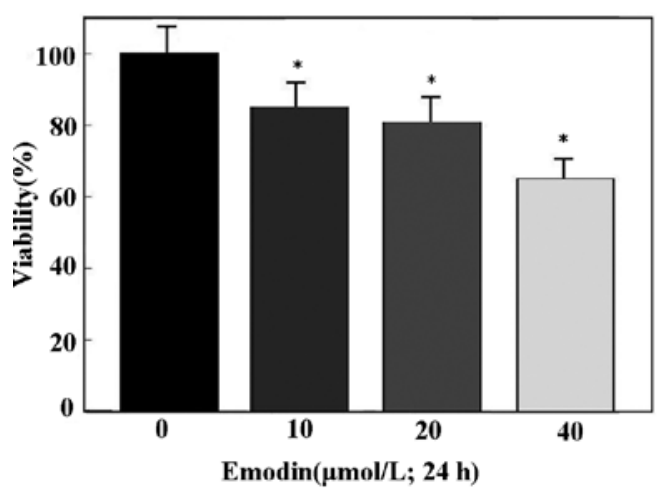

B

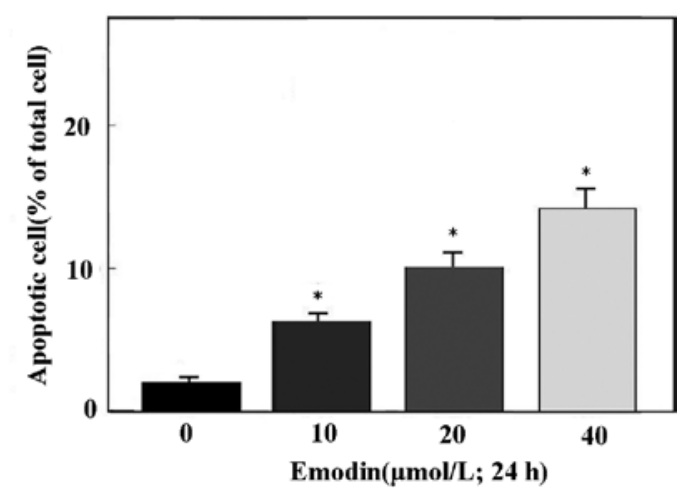

Figure 1. Evaluation of cell viability by WST-8 assay (A) and flow cytometry for apoptosis (B) by emodin treatment for 24 h. Data are presented as the mean $\pm \mathrm{SE}$ of three independent experiments. ${ }^{*} \mathrm{P}<0.05$ vs. control group.

the bicinchoninic acid method. Electrophoretic mobility shift assay (EMSA) was done by incubating $5 \mu \mathrm{g}$ of nuclear proteins with IRDye-700 labeled NF- $\mathrm{NB}$ oligonucleotide. The incubation mixture included $2 \mu \mathrm{g}$ of poly(deoxyinosinicdeoxycytidylic acid) in a binding buffer. The DNA-protein complex formed was separated from free oligonucleotide on $8.0 \%$ native polyacralyamide gel using buffer containing 50 mmoll $\mathrm{l}^{-1}$ Tris, $200 \mathrm{mmol} \cdot \mathrm{l}^{-1}$ glycine (pH 8.5), and $1 \mathrm{mmol} \cdot \mathrm{l}^{-1}$ EDTA and then visualized by Imager apparatus (Alpha Fluorochemical).

Experimental animals. Male athymic BALB/c nu/nu mice (4-6 weeks old) were obtained from Wenzhou Medical College. All animals were maintained in a sterile environment and cared for within the laboratory animal regulations of the Ministry of Science and Technology of the People's Republic of China (http:// www.most.gov.cn/kytj/kytjzcwj/200411/ t20041108_32465.htm). The food, water, and bedding for these immunocompromised mice were sterilized and changed at least once weekly.

Orthotopic implantation. Briefly, pancreatic cancer SW1990 cells were subcutaneously injected into the flanks of donor nude mice, after the tumor had reached a size of $\sim 1 \mathrm{~mm}^{3}$. Only macroscopically viable tissues from the periphery of the subcutaneous tumor were used for the orthotopic transplantation. Thirty recipient nude mice were anesthetized with pelltobarbitalum natricum and opened by a left longitudinal laparotomy. The spleen, together with the pancreatic tail, was gently exteriorized, and a tissue pocket in the pancreatic parenchyma was created by microscissors. One tumor fragment was placed into the tissue pocket in a way that it was entirely surrounded by normal pancreas. After careful relocation of the pancreas and spleen into the abdominal cavity, the animals were closed in 2 layers for the muscular layer and nonabsorbable stainless steel wound clips for the skin.

Experimental protocol. After 3 weeks of implantation, mice were randomized into 3 groups $(\mathrm{n}=10)$ : Control group, feed with $0.1 \%$ dimethyl sulfoxide (DMSO) $0.2 \mathrm{ml} /$ mouse. Emodin group I, emodin $20 \mathrm{mg} \cdot \mathrm{kg}^{-1}$ given by intragastric intubation. Emodin group II, emodin $40 \mathrm{mg} \cdot \mathrm{kg}^{-1}$ given by intragastric intubation. All treatment lasted for two weeks, thrice per week. Eight weeks after implantation, tumor weight, inhibition rate, and the presence of metastasis were evaluated respectively after the mice were sacrificed.

Immunohistochemical analysis. Sections were cut from paraffin-embedded pancreatic tumor tissues. Immunostaining was performed using primary antibodies specific for ki-67, NF- $\mathrm{KB}$, survivin and MMP-9 with appropriate dilutions and using normal host serum for negative controls, followed by staining with appropriate HRP-conjugated secondary antibodies. The slides were developed in diaminobenzidine and counterstained with a weak solution of haematoxylin solution stain. H\&E and terminal deoxynucleotidyl transferase-mediated dUTP nick end-labeling (TUNEL) for apoptosis were done also on paraffin-embedded tissue sections. The stained slides were dehydrated and mounted in permount and visualized on an microscope. Images were captured with an attached camera linked to a computer.

Statistical analysis. Data are represented as mean \pm SD for the absolute values or percent of controls. SPSS11.0 software was used for statistical analysis. ANOVA (Analysis of variance) was applied for comparison of the means of two or multiple groups, in which SNK (Student-Newman-Kewls) was further used for comparison of each two group. $\mathrm{P}<0.05$ was considered significant.

\section{Results}

Effect of emodin on cell proliferation. To test the effects of emodin on pancreatic cancer cell line SW1990. The SW1990 cells were treated with increasing concentrations of emodin $\left(10,20\right.$ and $\left.40 \mu \mathrm{mol} \cdot \mathrm{l}^{-1}\right)$ for $24 \mathrm{~h}$, viable cells were evaluated by WST-8 assay. As shown in Fig. 1A, pancreatic cancer cells growth were inhibited by emodin treatment in a dose-dependent manner. Furthermore, to assess whether the loss of cell viability could in part be due to apoptosis, flow cytometry was used to detect apoptosis in pancreatic cancer cells. Fig. 1B shows a significant increase in apoptotic cells closely paralleled by the loss of viable cells following emodin treatment. 
A

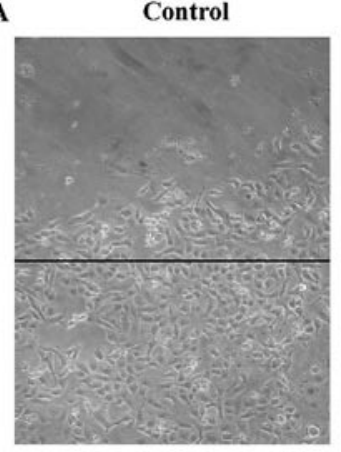

$\operatorname{Emodin}(10 \mu \mathrm{mol} / \mathrm{L})$

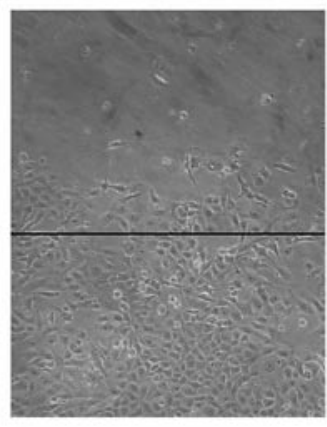

$\operatorname{Emodin}(20 \mu \mathrm{mol} / \mathrm{L})$

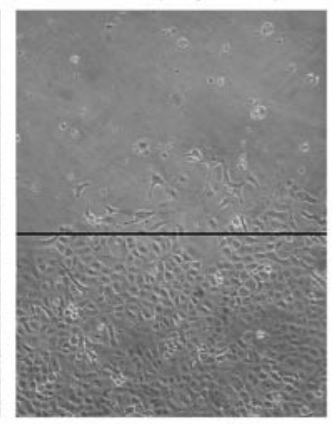

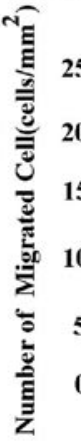

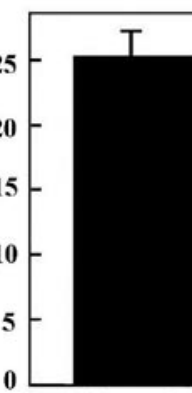

Control

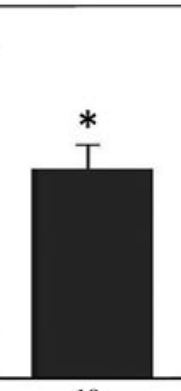

10

$\operatorname{Emodin}(\mu \mathrm{mol} / \mathrm{L})$

Figure 2. The anti-migration effect of emodin on pancreatic cancer cell line SW1990 was measured by scratch-wound healing assay. (A) Photographs indicate relative wound closure as monitored by visual examination using a Nikon phase-contrast microscope (x200). (B) The number of migrating pancreatic cancer SW1990 cells treated with increasing concentrations of emodin $\left(10,20\right.$ and $\left.40 \mu \mathrm{mol} \cdot \mathrm{l}^{-1}\right)$ for $2 \mathrm{~h}$, respectively. Columns, mean of three experiments; bars, SE. ${ }^{*} \mathrm{P}<0.05$ vs. control group.

Effects of emodin on the wound closure of pancreatic cancer cells in vitro. The ability of emodin to affect pancreatic cancer SW1990 cell migration was tested by means of a scratchwound model, the confluent monolayer of pancreatic cancer cells were wounded with a scratch, rinsed to remove debris, and incubated in the absence or presence of emodin (10, 20 and $40 \mu \mathrm{mol} \cdot \mathrm{l}^{-1}$ ) for $2 \mathrm{~h}$, and then incubated for an additional $24 \mathrm{~h}$. Images were taken from the same field at time zero and after $24 \mathrm{~h}$ (Fig. 2A). The results indicated that SW1990 cells treated with emodin exhibited significant decrease in migration in dose-dependent manner (Fig. 2B). The numbers of SW1990 cells treated by emodin migrated to the scratched area was significantly smaller than that of control.

Effect of emodin on the invasion of pancreatic cancer cells in vitro. To determine whether emodin could inhibit the invasive property of pancreatic cancer cells, we used transwell plates to measure the cell invasion property following emodin treatment. As shown in Fig. 3A and B, emodin inhibited the invasiveness of SW1990 cells through matrigel coated membrane in a concentration-dependent manner. To rule out the possibility that such inhibition is due to its cytotoxicity, the cell viability of emodin-treated cells was determined using WST-8 assay. The result showed that emodin had no significant effect on SW1990 cell viability at concentration of $40 \mu \mathrm{mol} \cdot \mathrm{l}^{-1}$ within $12 \mathrm{~h}$ of treatment (data not show), suggesting that emodin inhibits cell invasion without obvious cellular cytotoxicity.

Emodin inhibits $N F-\kappa B$ DNA-binding activity. As documented previously, constitutively active NF- $\mathrm{B}$ DNA binding activity was found in nuclear extracts from SW1990. To investigate whether emodin could abrogate constitutively expressed $\mathrm{NF}-\kappa \mathrm{B}, \mathrm{SW} 1990$ cells were treated with varying concentrations $\left(10,20\right.$ and $\left.40 \mu \mathrm{mol} \cdot \mathrm{l}^{-1}\right)$ of emodin for $24 \mathrm{~h}$ and subjected to gel shift assay (EMSA). As shown in Fig. 4, EMSA result showed a concentration-dependent inhibition by emodin in NF- $\mathrm{B}$ DNA binding activity in SW1990, which clearly suggest that emodin is effective in down-regulating $N F-\kappa B$ DNA-binding activity.

Survivin, caspase-3 and MMP-9 protein expression after emodin treatment in SW1990 cells. To ensure that the antiproliferation effects of emodin were not from toxicity but rather apoptosis, Western blot analysis for cleaved caspase-3 was performed on the SW1990 cell line. As shown in Fig. 5, the cleaved caspase-3 was markedly induced after emodin treatment in a dose-dependent manner. In an attempt to explore the mechanism of enhanced apoptotic process induced by treatment of cells with emodin. We next examined the antiapoptotic molecule survivin. Relative to control, survivin expression was down-regulated in cells exposed to emodin. To determine the potential molecular mediators of anti-migration, the change of MMP-9 protein expression was analyzed by Western blotting. Emodin treatment significantly decreased the MMP-9 levels in a dose-dependent manner.

Emodin inhibits tumor growth in nude mice. Building on the afore-mentioned results, which strongly support better killing of pancreatic cancer cells when exposed to emodin, we evaluated therapeutic advantage of emodin in BALB/c nu/ nu mice bearing orthotopically implanted pancreatic tumors. 
A

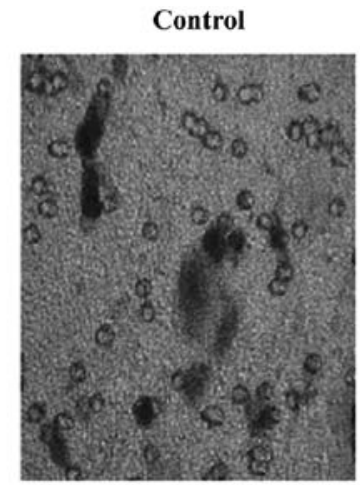

$\operatorname{Emodin}(10 \mu \mathrm{mol} / \mathrm{L})$

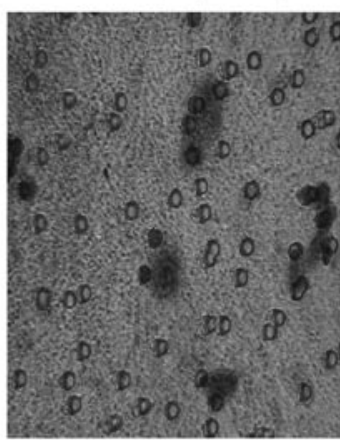

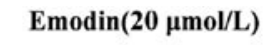

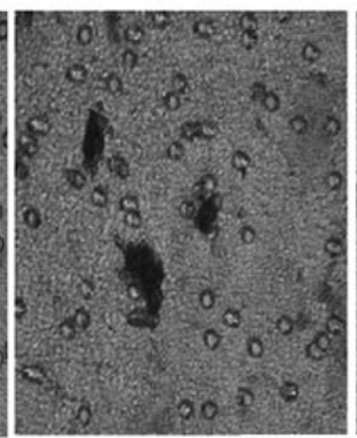

$\operatorname{Emodin}(40 \mu \mathrm{mol} / \mathrm{L})$

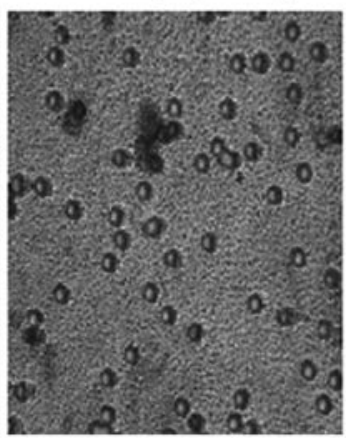

B

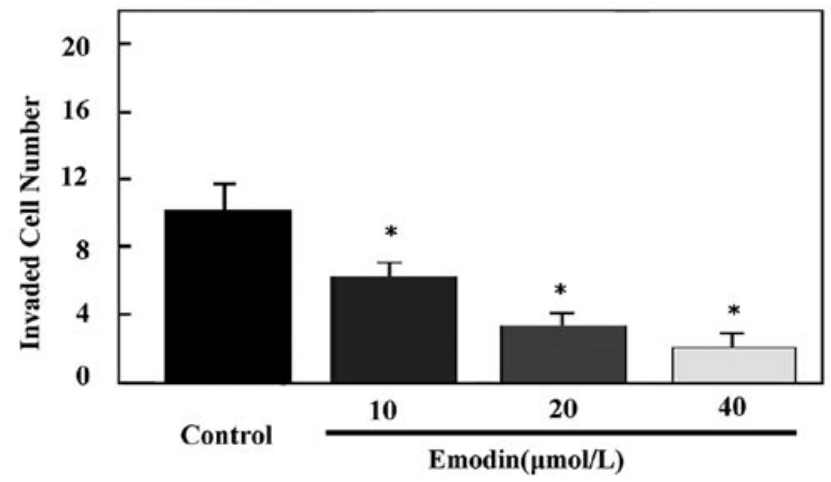

Figure 3. Inhibition of pancreatic cancer cells invasion by emodin. (A) Photographs of SW1990 cells after invasion through matrigel (x200). (B) Inhibitory effect of emodin on invasiveness of SW1990 cells. Cells $\left(2 \times 10^{5} / \mathrm{ml}\right)$ were seeded onto matrigel coated membranes of transwell plates and then treated with different concentrations of emodin $\left(10,20\right.$ and $\left.40 \mu \mathrm{mol}^{-1} \mathrm{l}^{-1}\right)$ for $2 \mathrm{~h}$. Cells that had invaded to the lower surface of the membranes were counted under a light microscope. Data are presented as means \pm SD. All experiments were done in triplicate. ${ }^{*} \mathrm{P}<0.05$ vs. control group.

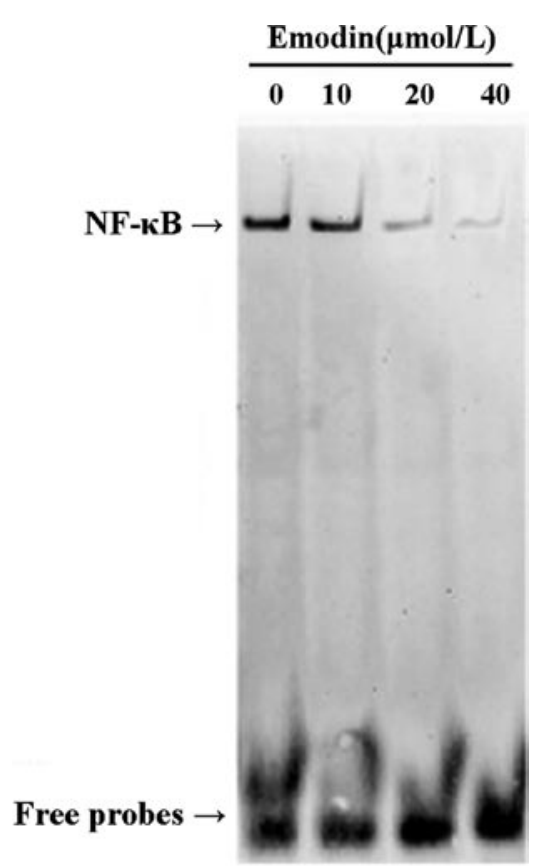

Figure 4. Nuclear proteins were prepared from the investigated cell line SW1990 after incubation with varying concentrations (10, 20 and $40 \mu$ moll $1^{-1}$ ) of emodin for up to $24 \mathrm{~h}$ as described in Materials and methods. Dose response by emodin in down-regulating NF- $\mathrm{KB}$ in cells expressing constitutive NF-кB.

Such studies have never been documented in vivo to the best of our knowledge. For in vivo experiment, 30 mice were divided into three groups as described in Materials and methods.

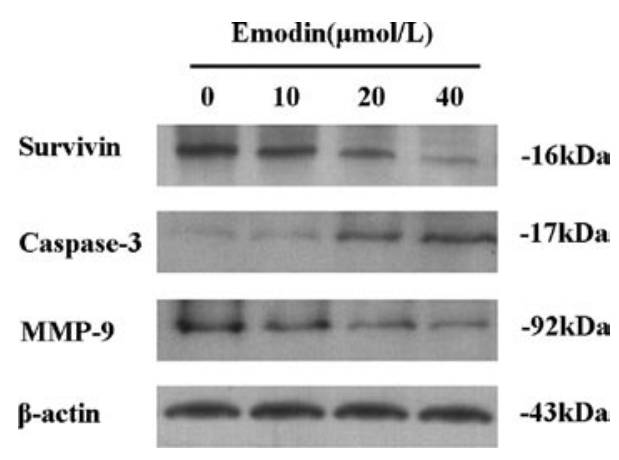

Figure 5. Western blot analysis of survivin, caspase-3 and MMP-9 in whole cell lysates of SW1990 cells after treated with various concentrations of emodin for $24 \mathrm{~h}$. $\beta$-actin protein as loading control is shown for each blot.

The results showed that after 14 days of treatment with emodin, no significant variation in body weight was detected, suggesting that emodin did not produce significant non-tumor toxicity in tumor-bearing mice. Next, we determined the mean pancreatic tumor weight immediately following euthanization in all treated groups. The average weights of tumors treated with emodin at 20 and $40 \mathrm{mg} \cdot \mathrm{kg}^{-1}$ were 1.442 and $1.215 \mathrm{~g}$, respectively, versus $1.651 \mathrm{~g}$ of negative control tumors, which correspond to 12.7 and $26.4 \%$ of inhibition. However, in the present experiment, administration of emodin at $20 \mathrm{mg} \cdot \mathrm{kg}^{-1}$ by gavage treatment resulted in nonsignificant reduction in the mean tumor weight compared with placebo treatment on completion of experiment, and a dose of $40 \mathrm{mg} \cdot \mathrm{kg}^{-1}$ emodin showed significant decrease $(\mathrm{P}<0.05)$ in tumor weight relative to control. 


\section{Control}
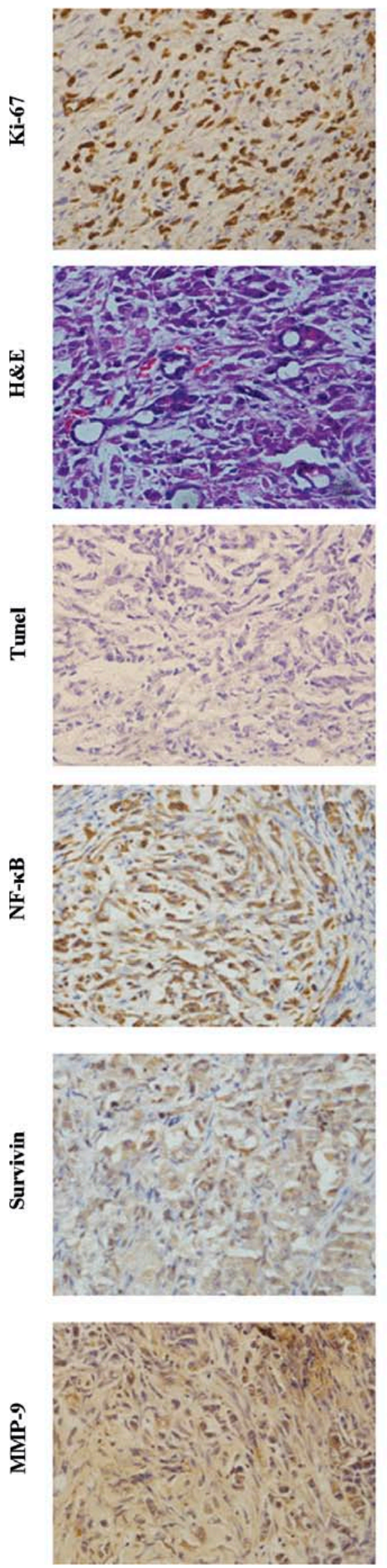

Emodin I
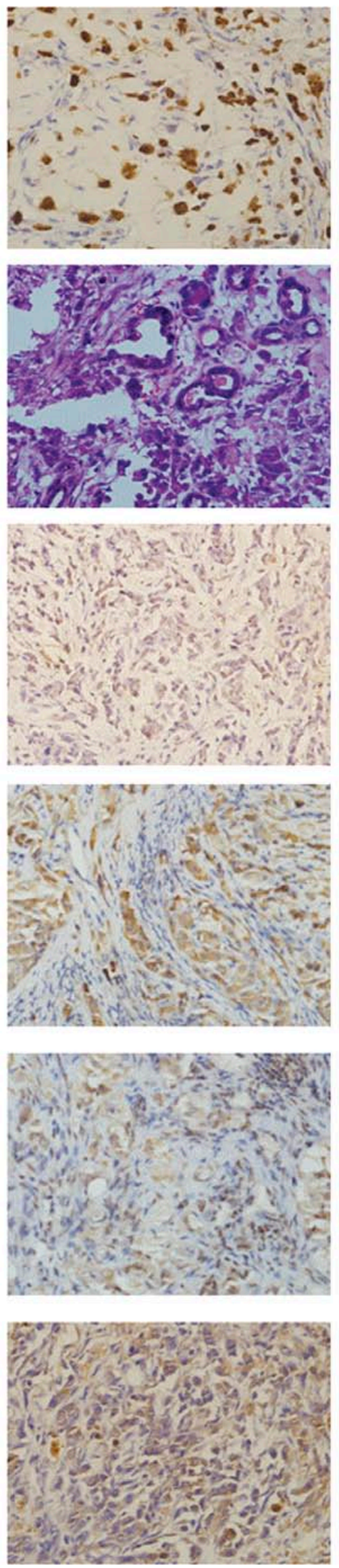

\section{Emodin II}
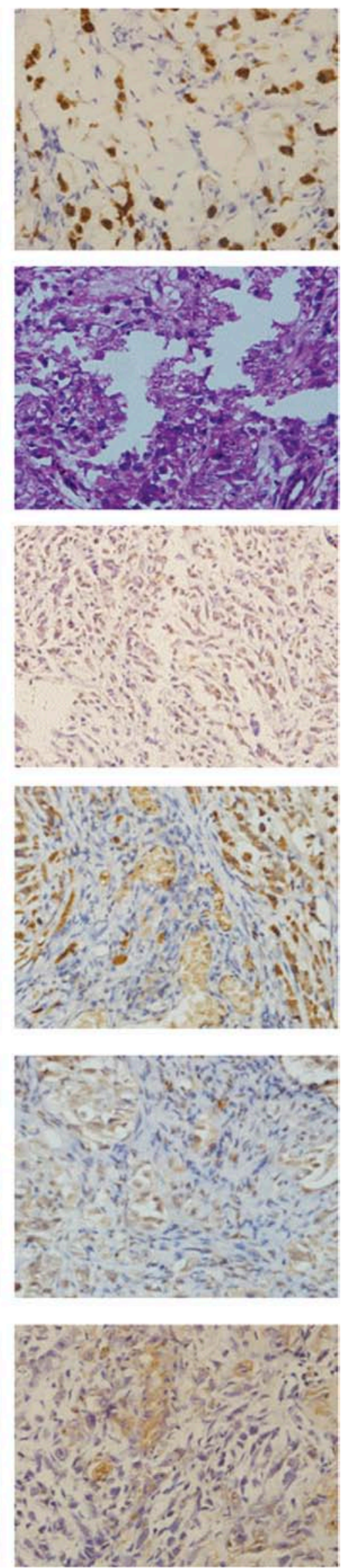

Figure 6. H\&E and immunohistochemistry for apoptosis by TUNEL, Ki-67, NF- $\mathrm{BB}$, survivin and MMP-9 protein expression in harvested tumors from tumorbearing nude mouse (original magnification, $\mathrm{x} 400$ ). Immunoreactivity towards all proteins were reduced in the emodin therapy group relative to their expression levels in the untreated control group. 
Table I. Effects of emodin on tumor weight and tumor invasion to visceral organs.

\begin{tabular}{|c|c|c|c|c|}
\hline Treatment & No. of animals & Tumor weight $(\mathrm{g})$ & Inhibitory rate $(\%)$ & Tumor invasion to visceral organs \\
\hline Control & 9 & $1.651 \pm 0.404$ & $9 / 9$ & $10 / 10(100 \%)$ \\
\hline \multicolumn{5}{|c|}{ Emodin dosed } \\
\hline $20 \mathrm{mg} \cdot \mathrm{kg}^{-1}$ & 10 & $1.442 \pm 0.387$ & 12.7 & $5 / 10(50 \%)^{\mathrm{a}}$ \\
\hline $40 \mathrm{mg} \cdot \mathrm{kg}^{-1}$ & 10 & $1.205 \pm 0.452^{\mathrm{a}}$ & 26.4 & $3 / 10(30 \%)^{\mathrm{a}}$ \\
\hline
\end{tabular}

Emodin $\left(20 \mathrm{mg} \cdot \mathrm{kg}^{-1}\right.$ and $\left.40 \mathrm{mg} \cdot \mathrm{kg}^{-1}\right)$ was administered p.o. for two weeks in mice bearing orthotopically implanted pancreatic tumors. Values are the means \pm standard error of $9-10$ mice. ${ }^{a} \mathrm{P}<0.05$ vs. control group.

Emodin also suppressed local invasion and peritoneal dissemination. Eight weeks after implantation, mice were sacrificed by cervical dislocation and their liver, spleen, thymus and small intestine quickly removed. Invasive metastases to visceral organs were observed manually and $\mathrm{H} \& \mathrm{E}$ staining. On autopsy, all of mice from the untreated control group showed evidence of nodal metastasis. However, the number of mice with visceral organ invasion of tumors was largely reduced by p.o. administered emodin (20 and 40 $\mathrm{mg} \cdot \mathrm{kg}^{-1}$ ) in mice bearing orthotopically implanted pancreatic tumors (Table I).

Tumor histology and immunohistochemistry after emodin treatment. H\&E evaluation of the tumors from all groups showed high-grade carcinoma associated with tumor apoptosis and necrosis (Fig. 6). In the control group, the tumor was largely viable with high mitosis and minimal intratumoral stroma. The peripheral tumor is composed of smaller nests or clusters of neoplastic cells. In contrast, in the group receiving emodin treatment $\left(40 \mathrm{mg} \cdot \mathrm{kg}^{-1}\right)$, large areas of cell debris due to marked tumor destruction in the tissue sections were seen. Similar but milder changes were also seen in the tumors from the group treated with emodin $\left(20 \mathrm{mg} \cdot \mathrm{kg}^{-1}\right)$. Furthermore, significant differences in percentage of TUNEL-positive cells were also noted in tumors derived from the emodin group relative to untreated animals $(\mathrm{P}<0.05)$. In addition, immunohistochemistry revealed significant reduction in $\mathrm{Ki}-67, \mathrm{NF}-\kappa \mathrm{B}$, survivin and MMP-9 in tumors derived from mice treated with emodin $(\mathrm{P}<0.05)$ compared with untreated mice.

\section{Discussion}

Several studies have manifested that emodin exerts antiproliferative effect on several cancer cells, which are mediated through the induction of apoptosis. In agreement with a previous study (8), we documented that emodin within the range of tested concentrations, is able to directly inhibit cell viability dose-dependently in human pancreatic cancer cell line SW1990 in vitro. Furthermore, inhibition of cell growth was correlated with apoptotic cell death. By fluorescenceactivated cell sorting analysis, our results showed emodin increased the percentages of both early and late apoptotic/ necrotic cells in a dose-dependent manner. In agreement with the results of FACS, apoptosis induced by emodin in pancreatic cells was validated by activation of caspase-3. In addition to in vitro results, we show for the first time, that emodin is also an effective antitumor agent in our orthotopic tumor model, and significant differences in percentage of TUNEL-positive cells were noted in tumors derived from the emodin group relative to untreated animals. However, no significant variation in body weight was detected in animals after 14 days of treatment with emodin. All these results show that emodin is a potentially powerful anti-cancer drug and apoptosis inducer with low toxicity and very few side effects.

The question remains as to how emodin induces apoptosis in SW1990 cells. The prosurvival molecule survivin, a member of the inhibitor of apoptosis protein (IAP) family, is associated with poor prognosis and increased tumor recurrence (9). Survivin could act directly on caspases and mainly suppress the activity of caspase-3 and -7 (10). Growing evidence suggests that survivin is responsible for drug resistance in cancer cells $(11,12)$. A previous study showed that curcumin directed against survivin could enhance chemosensitivity to gemcitabine in pancreatic cancer (13). In the current study, we showed that emodin down-regulated survivin and increased the expression of cleaved caspase-3 in SW1990 cells. In addition, our in vivo results showed that emodin abrogated the expression of survivin and increased apoptotic cells, which demonstrates that inhibition of survivin is likely to be associated with the mechanism of emodin as an apoptosis inducer in pancreatic cancer.

Metastasis is one of the hallmarks of cancer. Inhibition of metastasis has become an attractive therapeutic alternative for the treatment of cancers. The process of metastasis consists of a complex cascade of interdependent steps. Cell invasion, the process of translocation of neoplastic cells across extracellular matrix barriers, is an essential biological process required for tumor metastasis. For invasion to occur, a cancer cell requires increased migration activity, loss of cell-cell adhesion with a concomitant gain of cell-matrix adhesion, and an increased expression and activation of extracellular proteases capable of degrading the ECM (14). Through their degradation of ECM proteins, the MMPs, a group of zinc-dependent ECM degrading enzymes, play major roles in the regulation of cancer cell migration, ECM invasion, and metastasis (15). In particular, MMP-9 is thought to be critical for degrading ECM proteins and thus perform an important role in cancer cell invasion and metastasis (16). Moreover, there is substantial evidence on the inhibition of MMP-9 and suppression of invasiveness and metastasis of cancer cells using various chemopreventive agents such as genistein and aspirin $(17,18)$. In the present 
study, we found that nontoxic levels of emodin efficiently suppressed the invasiveness of pancreatic cancer cells. Furthermore, we tested the anti-metastatic effect of emodin by using an in vivo model of peritoneal metastasis in nude mice. Our study documents, for the first time, that emodin can effectively suppress the growth of peritoneal metastasis in this experimental condition. Next we showed that emodin inhibited MMP-9 expression both in vitro and in vivo, which provided an explanation for its suppression of invasiveness of pancreatic cancer cells observed in the cell invasion assay and orthotopic tumor model.

As reported, the rapid-acting primary transcription factor nuclear factor $-\kappa \mathrm{B}(\mathrm{NF}-\kappa \mathrm{B})$ is constitutively active in most pancreatic cancer cell lines (19). Furthermore, NF- $\kappa B$ activation has been demonstrated in animal models of pancreatic cancer and in human pancreatic cancer tissue $(13,20)$. There is emerging evidence suggesting that $\mathrm{NF}-\kappa \mathrm{B}$ has become an attractive target for chemoprevention and its modulation for pancreatic cancer prevention. First, $N F-\kappa B$ expression has been implicated in the regulation of survivin expression and apoptosis in human pancreatic cancer, which underscores the role of $\mathrm{NF}-\kappa \mathrm{B}$ activation in mediating chemoresistance. Second, tumor invasion is regulated by numerous NF- $\kappa \mathrm{B}-$ regulated gene products, including matrix metalloproteinases (MMPs). It has been reported that MMP-9 expression is regulated transcriptionally through $\mathrm{NF}-\kappa \mathrm{B}$ elements within the MMP-9 gene (21). Third, it has been shown that many conventional cancer chemotherapeutic agents such as gemcitabine activate $\mathrm{NF}-\kappa \mathrm{B}(13,20,22)$, making gemcitabine less effective in cancer cells. Finally, the evidence indicates the important role of $\mathrm{NF}-\kappa \mathrm{B}$ in pancreatic cancer and suggests that agents that block $N F-\kappa B$ activation could reduce chemoresistance and metastasis in pancreatic cancer and possibly could be used as a therapeutic regimen for pancreatic cancer. Previous studies have demonstrated that curcumin (13), thymoquinone (20) and hyperthermia (22) sensitized pancreatic cancer cells to chemotherapeutic drugs through down-regulation of $\mathrm{NF}-\kappa \mathrm{B}$. In the present study, we found that emodin abrogates $\mathrm{NF}-\kappa \mathrm{B}$ activation in pancreatic cancer SW1990 cells as well as in other cancer cells (23). In addition, our in vitro results showed that emodin treatment inhibits $\mathrm{NF}-\kappa \mathrm{B}$ and exerts antiproliferative and antimetastatic effects in SW1990 cells, suggesting that inhibition of NF- $\mathrm{BB}$ by emodin is mechanistically associated with sensitization of pancreatic cancer cells to apoptosis and inhibition of pancreatic cancer cell metastasis. However most importantly, these in vitro results, such as antitumor activity and inactivation of $\mathrm{NF}-\kappa \mathrm{B}$, were recapitulated in vivo using the orthotopic mouse model, which provides a scientific rationale for therapeutic exploitation of our strategy for the treatment of patients with pancreatic cancer. These results provide strong molecular in vitro and in vivo evidence in support of our hypothesis that inactivation of $\mathrm{NF}-\kappa \mathrm{B}$ signaling pathway by emodin is likely to be an important and novel strategy for the treatment of pancreatic cancer.

In conclusion, our current findings are consistent with the hypothesis that emodin could down-regulate antiapoptotic and metastatic proteins that are transcriptionally regulated by $\mathrm{NF}-\kappa \mathrm{B}$, resulting in loss of pancreatic cancer cells to survive and metastasize. Our in vitro findings along with in vivo results provide support for further development of emodin as an adjunct to conventional chemotherapeutics by targeted inactivation of NF- $\kappa \mathrm{B}$ for treatment of human pancreatic tumors and initiation of clinical trials.

\section{Acknowledgments}

The study was supported by Zhejiang Provincial Natural Science Foundation of China (Grant No. Y2080708). We thank Yong-guo Jin, Qiu-sha He and Jin-dan Wang for helpfully assistance.

\section{References}

1. Rivera F, López-Tarruella S, Vega-Villegas ME, et al: Treatment of advanced pancreatic cancer: from gemcitabine single agent to combinations and targeted therapy. Cancer Treat Rev 35: 335-339, 2009.

2. Jemal A, Siegel R, Ward E, et al: Cancer statistics, 2007. CA Cancer J Clin 57: 43-66, 2007.

3. Demirezer LO, Kuruüzüm-Uz A, Bergere I, et al: The structures of antioxidant and cytotoxic agents from natural source: anthraquinones and tannins from roots of Rumex patientia. Phytochemistry 58: 1213-1217, 2001.

4. Huang Q, Lu G, Shen HM, et al: Anti-cancer properties of anthraquinones from rhubarb. Med Res Rev 27: 609-630, 2007.

5. Li J, Liu P, Mao H, et al: Emodin sensitizes paclitaxel-resistant human ovarian cancer cells to paclitaxel-induced apoptosis in vitro. Oncol Rep 21: 1605-1610, 2009.

6. Ko JC, Su YJ, Lin ST, et al: Suppression of ERCC1 and Rad51 expression through ERK1/2 inactivation is essential in emodinmediated cytotoxicity in human non-small cell lung cancer cells. Biochem Pharmacol 79: 655-664, 2010.

7. Chun-Guang W, Jun-Qing Y, Bei-Zhong L, et al: Anti-tumor activity of emodin against human chronic myelocytic leukemia K562 cell lines in vitro and in vivo. Eur J Pharmacol 627: 33-41, 2010.

8. Chen H, Wei WT, Guo YF, et al: Enhanced effect of gemcitabine by emodin against pancreatic cancer in vivo via cytochrome C-regulated apoptosis. Oncol Rep 25: 1253-1261, 2011.

9. Lee MA, Park GS, Lee HJ, et al: Survivin expression and its clinical significance in pancreatic cancer. BMC Cancer 5: 127, 2005.

10. Yang LQ, Fang DC, Wang RQ, et al: Effect of NF-kappaB, survivin, Bcl-2 and Caspase 3 on apoptosis of gastric cancer cells induced by tumor necrosis factor related apoptosis inducing ligand. World J Gastroenterol 10: 2-25, 2004.

11. Liu X, Gao R, Dong Y, et al: Survivin gene silencing sensitizes prostate cancer cells to selenium growth inhibition. BMC Cancer 10: 418, 2010.

12. Cheung $\mathrm{CH}$, Sun X, Kanwar JR, et al: A cell-permeable dominant-negative survivin protein induces apoptosis and sensitizes prostate cancer cells to TNF- $\alpha$ therapy. Cancer Cell Int 10: 36, 2010.

13. Kunnumakkara AB, Guha S, Krishnan S, et al: Curcumin potentiates antitumor activity of gemcitabine in an orthotopic model of pancreatic cancer through suppression of proliferation, angiogenesis, and inhibition of nuclear factor-kappaB-regulated gene products. Cancer Res 67: 3853-3861, 2007.

14. Böhle AS and Kalthoff H: Molecular mechanisms of tumor metastasis and angiogenesis. Langenbecks Arch Surg 384: 133-140, 1999.

15. Montgomery AM, Mueller BM, Reisfeld RA, et al: Effect of tissue inhibitor of the matrix metalloproteinases-2 expression on the growth and spontaneous metastasis of a human melanoma cell line. Cancer Res 54: 5467-5473, 1994.

16. Ho LL, Chen WJ, Lin-Shiau SY, et al: Penta-O-galloyl-beta-Dglucose inhibits the invasion of mouse melanoma by suppressing metalloproteinase-9 through down-regulation of activator protein-1. Eur J Pharmacol 453: 149-158, 2002.

17. Alhasan SA, Aranha $\mathrm{O}$ and Sarkar FH: Genistein elicits pleiotropic molecular effects on head and neck cancer cells. Clin Cancer Res 7: 4174-4181, 2001.

18. Abiru S, Nakao K, Ichikawa T, et al: Aspirin and NS-398 inhibit hepatocyte growth factor-induced invasiveness of human hepatoma cells. Hepatology 35: 1117-1124, 2002. 
19. Liptay S, Weber CK, Ludwig L, et al: Mitogenic and antiapoptotic role of constitutive NF-kappaB/Rel activity in pancreatic cancer. Int J Cancer 105: 735-746, 2003

20. Banerjee S, Kaseb AO, Wang Z, et al: Antitumor activity of gemcitabine and oxaliplatin is augmented by thymoquinone in pancreatic cancer. Cancer Res 69: 5575-5583, 2009.

21. Aggarwal BB: Nuclear factor-kappaB: the enemy within. Cancer Cell 6: 203-208, 2004.
22. Adachi S, Kokura S, Okayama T, et al: Effect of hyperthermia combined with gemcitabine on apoptotic cell death in cultured human pancreatic cancer cell lines. Int J Hyperthermia 25: 210-219, 2009.

23. Kuo TC, Yang JS, Lin MW, et al: Emodin has cytotoxic and protective effects in rat C6 glioma cells: roles of Mdrla and nuclear factor kappaB in cell survival. J Pharmacol Exp Ther 330: 736-744, 2009. 